Article

\title{
Oscillation Damping for Wind Energy Conversion System with Doubly Fed Induction Generator Association with Synchronous Generator
}

\author{
Farag K. Abo-Elyousr ${ }^{1} * * \mathbb{D}$, Hossam S. Abbas ${ }^{1}$, Ali M. Yousef ${ }^{1}$, Nguyen Vu Quynh ${ }^{2, *(\mathbb{D} \text {, }}$ \\ Ziad M. Ali ${ }^{3,4}$ and Muhammad Shahzad Nazir ${ }^{5}$ \\ 1 Electrical Engineering Department, Faculty of Engineering, Assiut University, Assiut 71516, Egypt; \\ hossam.abbas@aun.edu.eg (H.S.A.); drali_yousef@yahoo.com (A.M.Y.) \\ 2 Electrical and Electronics Department, Lac Hong University, Dong Nai, Vietnam \\ 3 Electrical Engineering Department, College of Engineering at Wadi Addawaser, \\ Prince Sattam bin Abdulaziz University, Wadi Addawser 11991, Saudi Arabia; \\ dr.ziad.elhalwany@aswu.edu.eg \\ 4 Electrical Engineering Department, Aswan Faculty of Engineering, Aswan University, Aswan 81542, Egypt \\ 5 Faculty of Automation, Huaiyin Institute of Technology, Huai'an 223003, China; nazir@hyit.edu.cn \\ * Correspondence: farag@aun.edu.eg (F.K.A.-E.); vuquynh@lhu.edu.vn (N.V.Q.)
}

Received: 26 August 2020; Accepted: 22 September 2020; Published: 27 September 2020

\begin{abstract}
The main purpose of this paper is to enhance the operation of renewable wind energy conversion (WEC) systems connected to power systems. To achieve this, we consider a linear quadratic Gaussian (LQG) control approach for regulating the effects of a WEC system with doubly fed induction generator (DFIG) on the synchronous generator (SG) rotor speed of the interconnected power system. First, we present the mathematical formulation of the interconnected power system comprises a single synchronous generator and a wind turbine with DFIG connected to an infinite bus bar system through a transmission line. We consider that the system is operated under various loading conditions and parameters variation. Second, a frequency damping oscillation observer is designed via Kalman filtering together with an optimal linear quadratic regulator to mitigate the impacts of the WEC system on the SG rotor speed. The performance of the developed interconnected power system is simulated using a MATLAB/SIMULINK environment to verify the effectiveness of the developed controller. In comparison with previously reported results, the proposed approach can stabilize the interconnected power system within $1.28 \mathrm{~s}$ compared to $1.3 \mathrm{~s}$ without the DFIG.
\end{abstract}

Keywords: rotor angle deviations; load frequency control (LFC); linear quadratic Gaussian (LQG); multi-area power systems

\section{Introduction}

Generally, power system oscillations are due to the absence of damping torques. In addition, the use of hybrid distributed energy resources (DERs) is at a level of importance to meet the demand side. This problem is a real challenge in wind energy conversion (WEC) systems due to the fluctuations of the wind, which can change the power system inertia [1-3]. Moreover, wind energy has an intermittent nature, which can affect the generation/load profile [4]. That results in rotor oscillations of synchronous machines and causes oscillation in other power system variables such as frequency, voltage, transmission line power, etc. Normally, interconnected power system frequency digression is within the range of 0.1 to $2 \mathrm{~Hz}$ [5].

Several techniques have been used in the literature to design load frequency control (LFC) systems. Shintai et al. (2014), designed a generic oscillation damping for distributed generators 
via a virtual synchronous approach [3]. In ref. [6], Abo-Elyousr et al. (2019), introduced a novel approach for associating a virtual inertia resource with a conventional interconnected power system with synchronous generator (SG) in a two-area system. Similar work was conducted in [7] for massless inertia photovoltaics. Attaya et al. (2019) conducted a research to enhance the ancillary services by renewables association with conventional synchronous generator [8]. The authors of [8] concluded that renewable energy could positively tackle the frequency and voltages events, respectively. In ref. $[9,10]$, a lead-lag compensator was proposed to handle the LFC problem. Optimal pole placement control has been employed in [11] for improving dynamic performance. Finally, generic positive real systems were discussed in [12].

The application of virtual or massless inertia generators have been studied in the literature. Massless inertia resources are defined as the resources which have inverter and thereby help provide energy to the grid. Doubly fed induction generator (DFIG) based wind turbines, particularly, those used to extract the maximum power without reserve, lies in this area of energy resources as the rotor is connected to the grid via bidirectional converters. The authors of $[13,14]$ discussed the impact of DFIG based wind turbines, they concluded that robust control is necessary to handle the effects of the DFIG onto the frequency of the interconnected power system without discussing other effects related to the deviations the synchronous generator (SG) rotor speeds. Conventional synchronous generators can be paralleled with wind turbine based generators; however, DFIG based wind turbine can significantly affect the system frequency. Therefore, proper control is necessary to avoid energy or speed variations of wind turbine, which can twist the rotor of synchronous machines.

The main problem that is considered in this work emerges from the intermittent nature of WEC systems, which renders the generation/load imbalance and can lead to frequency digressions problems. With DFIG-based wind turbines, the high penetration of wind energy in conventional power systems reduces the overall system inertia [14-16]. Hence, it is important to accurately monitoring wind power sharing impact on the LFC to avoid SG rotor buckling problems [17-19].

In this work, we develop a load frequency controller to reduce the deviations of the rotor speed of synchronous machines in power systems connected to WEC system due to wind energy penetration and fluctuations. Another issue is related to the effect of DFIG-based wind turbines onto the utility grid frequency, which results in faster changes in the hybrid system frequency due to the changes of the shared load demands.

Recently, several works have been conducted to allow variable speed wind turbines to contribute effectively onto load frequency regulations. A meta-heuristic algorithm based on ant colony was considered in [20] for a two-area thermal system with DFIG-based wind turbine. A load frequency controller design for a hydrothermal interconnected power system was introduced in [14] using an improved harmony algorithm, in which one area from the interconnected power system has a DFIG-based wind turbine. Generally, meta-heuristic algorithms consume time in an off-line manner to decide appropriate values for the PI controllers. A literature survey of renewable energy resources including wind energy participation in LFC problem was presented in [21]. The participation of DFIG-based wind turbine in system frequency regulation by pitch angle control in LFC was introduced in [22]. However, the results were based on isolated networks. In addition, different methodologies of DFIG participation in the grid frequency were presented in [23]. A load frequency control using maximum integer linear programing was developed in [24], which can handle strong wind penetrations. A method to improve the DFIG-based wind turbine dynamic stability utilizing crowbar and other hardware equipment parts was introduced in [25]. Furthermore, the impact of DFIG-based wind turbine on frequency regulation based input-to-state stability formulation was investigated in [1].

The underlying problems include the uncertainty of the system parameters, noisy measurements, and fluctuations of the wind speed. In practice, linear quadratic Gaussian (LQG) control has a significant impact on improving system performances when noise and uncertainties are imposed. Recently, LQG was utilized successively to solve many engineering problems, which motivates the authors to use the LQG technique to damp out the SG rotor speed deviations of an SG combined with 
DFIG-based wind turbine connected to infinite bus. LQG has been used in [26] to design a robust control of an isolated wind-diesel system. In ref. [27], LQG was combined with a coefficient diagram method to solve a distributed LFC problem. The load and generation balance problem was proposed for two area interconnected power system in [28] and LQG with genetic algorithm was used in [29] to solve the LFC issues in the considered power system. A load frequency controller for multi-area power system via LQG was also used in [30].

The main goals of this work are outlined as follows: (1) To develop a controller which can be operated under variable wind speeds, several wind power penetrations, and different system operating conditions. In this concern, the challenge is how to guarantee the stability of the system by damping the frequency due to the deviations of the SG rotor speed. This can increase the sustainability of the renewable WEC power system. (2) To successfully suppress the SG rotor speed and angle deviations so that the SG output power and frequency deviations can be restored within satisfactory settling times. This can improve power sharing mechanism among both machines and thereby reducing the speed deviations of the DFIG based machine.

Unlike the approaches in $[1,2,5-14,20-24]$ that considered the availability of all the state variables online, which is not usually the case in practice, we use the Kalman filter to extract the state information from the measured output of the system. Despite the rich literature regarding wind turbines contributions into LFC, there is a lack in the studies, which consider the impact of the wind energy on the rotor speed of conventional SGs. In addition, DFIG operating at maximum power point tracking cannot regulate frequency under different load demands. Then, the rate of change of the frequency and hence the SG rotor speed deviations might increase significantly. Our approach proposed in this work tries to handle these issues; to carry that out, a dynamic model formulation in state space representation for the DFIG based wind turbine connected to a convention synchronous generator is developed, which is used to tackle the load power sharing among the two machines. Next, a controller is developed via an LQG approach to stabilize the rotor speed of the SG. The effectiveness of the developed controller is verified through a comparison with the open loop system and a pole placement controller. The low complexity of the developed controller can avoid several signal measurements as it relies on the Kalman filter observer and receives few signals from the leader synchronous generator.

The remainder of this work is organized as follows. The problem description was presented in Section 2. The considered system modeling is introduced in Section 3. Problem formulation is addressed in part 4. Simulated results and discussions are given in Sections 5 and 6, respectively. Finally, the conclusions are given in Section 7.

\section{System Description}

Figure 1 shows a schematic diagram of the interconnected power system under study. It consists of a conventional synchronous generator combined with DFIG based wind turbine generator $[2,10]$. As DFIG has been populating within distribution systems or at the level of hybrid microgrids to provide active or reactive powers; however, the DFIG based wind turbine impact on thermal units' rotor speed, and hence the onward output frequency with the infinite bus bars, was rarely addressed before. A target of this study is thus to develop a robust controller such that the effect of the DFIG based wind turbine on system leader SG can be manipulated appropriately. Herein, since the SG parameters are dependent on the operating conditions, which adds more uncertainty; therefore, SG rotor speed response is to be tested at several linearized step demands at heavy, light, lag, and lead power factor loading conditions. The parameters of the SGs change heavily with the loading conditions. The derivation of such parameters in terms of the loading conditions is beyond the scope of the current work. At a loading condition of $\mathrm{P}=1 \mathrm{pu}$ and $\mathrm{Q}=0.25 \mathrm{pu}$, the parameters are given as follows: $X_{d}=1.6 \mathrm{pu}, X_{q}=1.55 \mathrm{pu}, X^{\prime}{ }_{d}=0.32 \mathrm{pu}, X_{e}=0.4 \mathrm{pu}, \omega_{o}=377 \mathrm{rad} / \mathrm{s}, M=10, D=0, T_{A}=0.06$, $K_{A}=25, T_{t}=0.27, T_{g}=0.08, \mathrm{R}=1.82$, in which $X_{d}$ and $X_{q}$ are the direct and quadrature axis reactances, $X_{d}^{\prime}$ is the transient direct axis reactance, $X_{e}$ is the armature leakage reactance, $\omega_{o}$ is the synchronous speed, $M$ is the moment of inertia, $D$ is the damping coefficient, and $R$ is the frequency regulation [2]. 


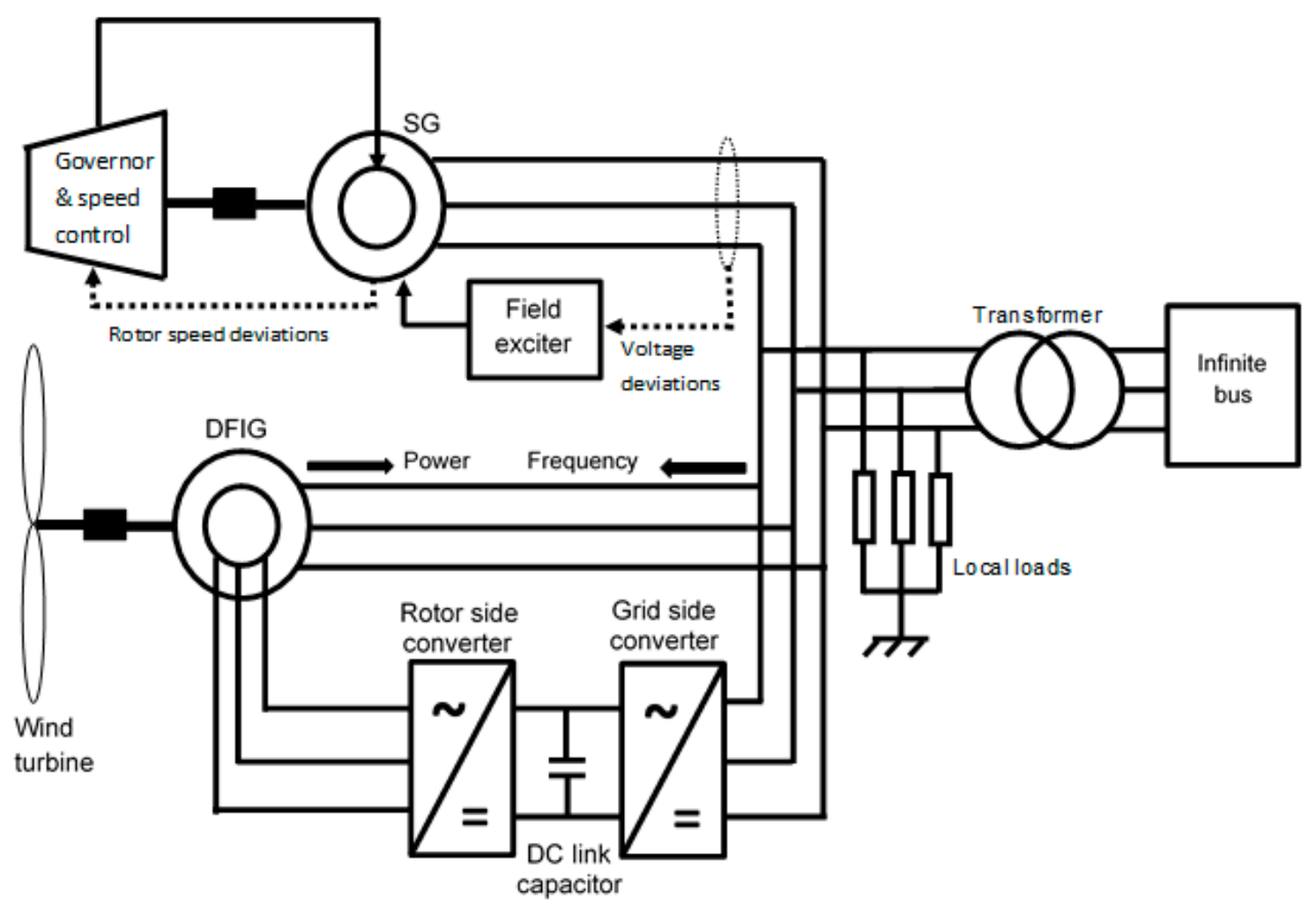

Figure 1. Structure diagram of the hybrid distributed energy resource.

\section{System Modeling}

A major target of this study is the formulation of two combined machines such that the small signal stability and performance are investigated. Figure 2a demonstrates the block diagram of the conventional SG Concordia model, which comprises the primary frequency control, power system stabilizer (PSS), and the power that can be supported by the DFIG based machine to meet the load demands. The mechanical energy of the DFIG is given in Equation (1), in which $H_{e}$ is the inertia constant of the DFIG machine, $\Delta P_{N C}$ is the DFIG supported power, and $\Delta P_{N C \text {,ref }}$ is the reference command power for the DFIG machine:

$$
2 H_{e} \frac{d \omega_{d}}{d t}=\Delta P_{N C, r e f}-\Delta P_{N C}
$$

Provided that the DFIG rotor speed deviations are regulated by a PI controller $\left(K_{w p}, K_{w i}\right)$, the wind turbine transfer function is given in Equation (2), in which $\tau_{a}$ is the wind turbine time constant [14]:

$$
\frac{1}{1+s \tau_{a}}
$$

Combining Equations (1) and (2), and the PI speed regulator, the DFIG based wind turbine model is obtained as shown in Figure $2 b$. The development of the system described in Figure 1 is thus tailored in the developed modified Concordia configuration demonstrated in Figure 2c [2]. The system demonstrates a combination of automatic voltage regulator (AVR), simple frequency control loop, and DFIG based wind turbine model $[9,20]$. Another important point is related power electronic converters that will be used for integrating wind to the AC grid, thereof the washout filter and the frequency measurements are used as a decentralized power sharing mechanism. The washout filter helps consider the SG frequency impact on the power delivered to the rotor side of the DFIG based machine via an inverter in a manner that approximates the derivative of the input SG rotor speed signal [31,32]. 


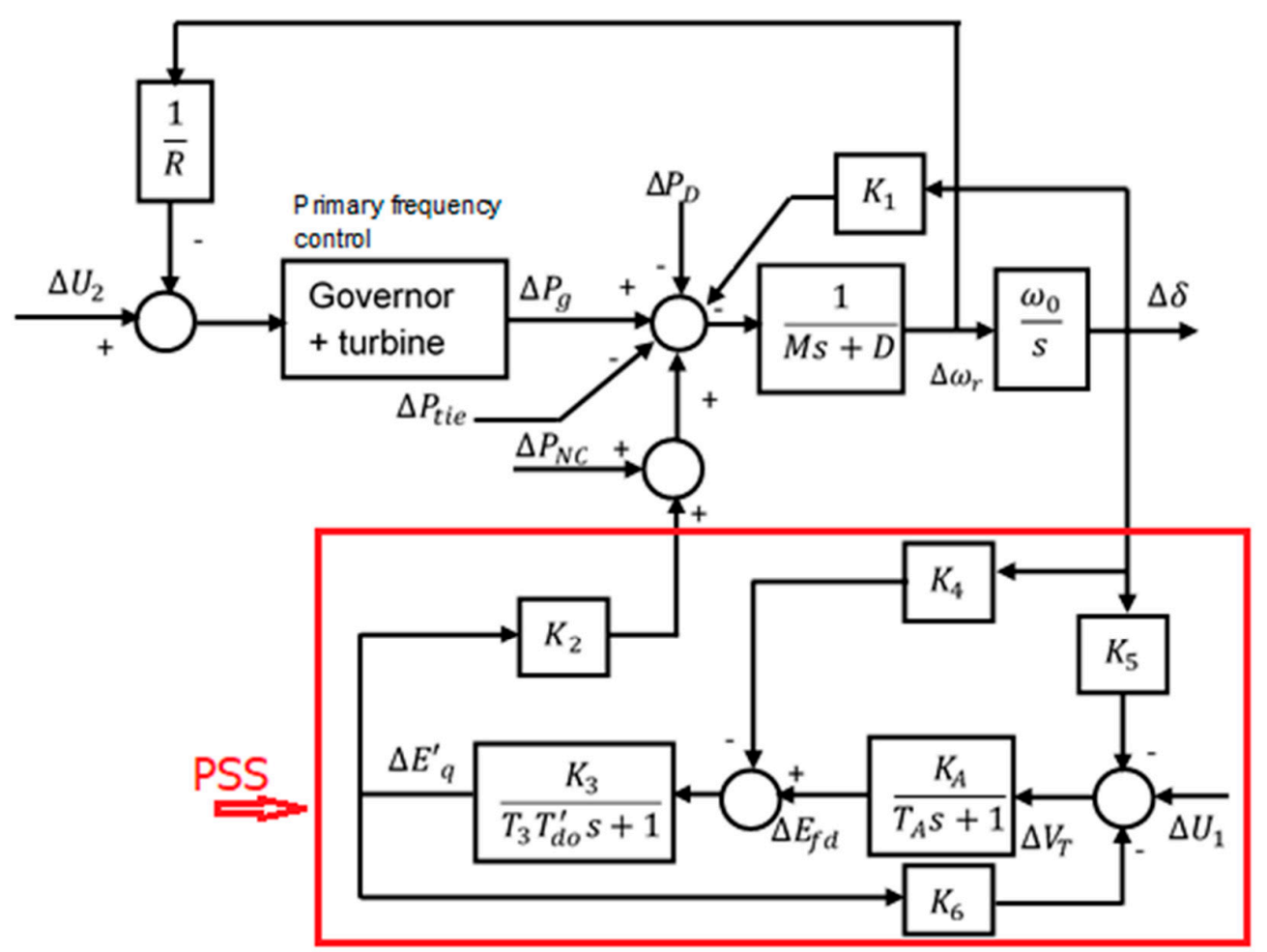

(a) Synchronous generator block diagram.

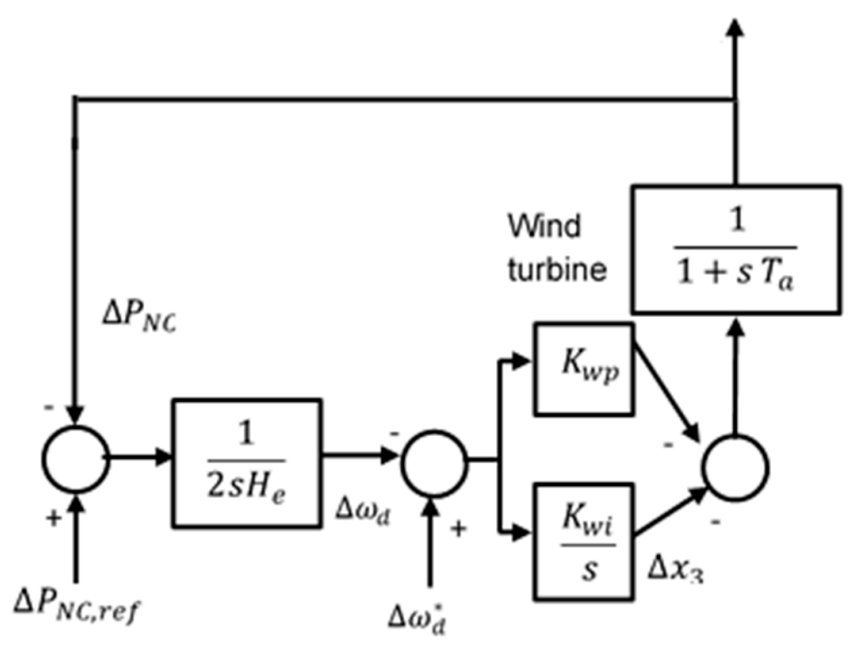

(b) DFIG resource block diagram.

Figure 2. Cont. 


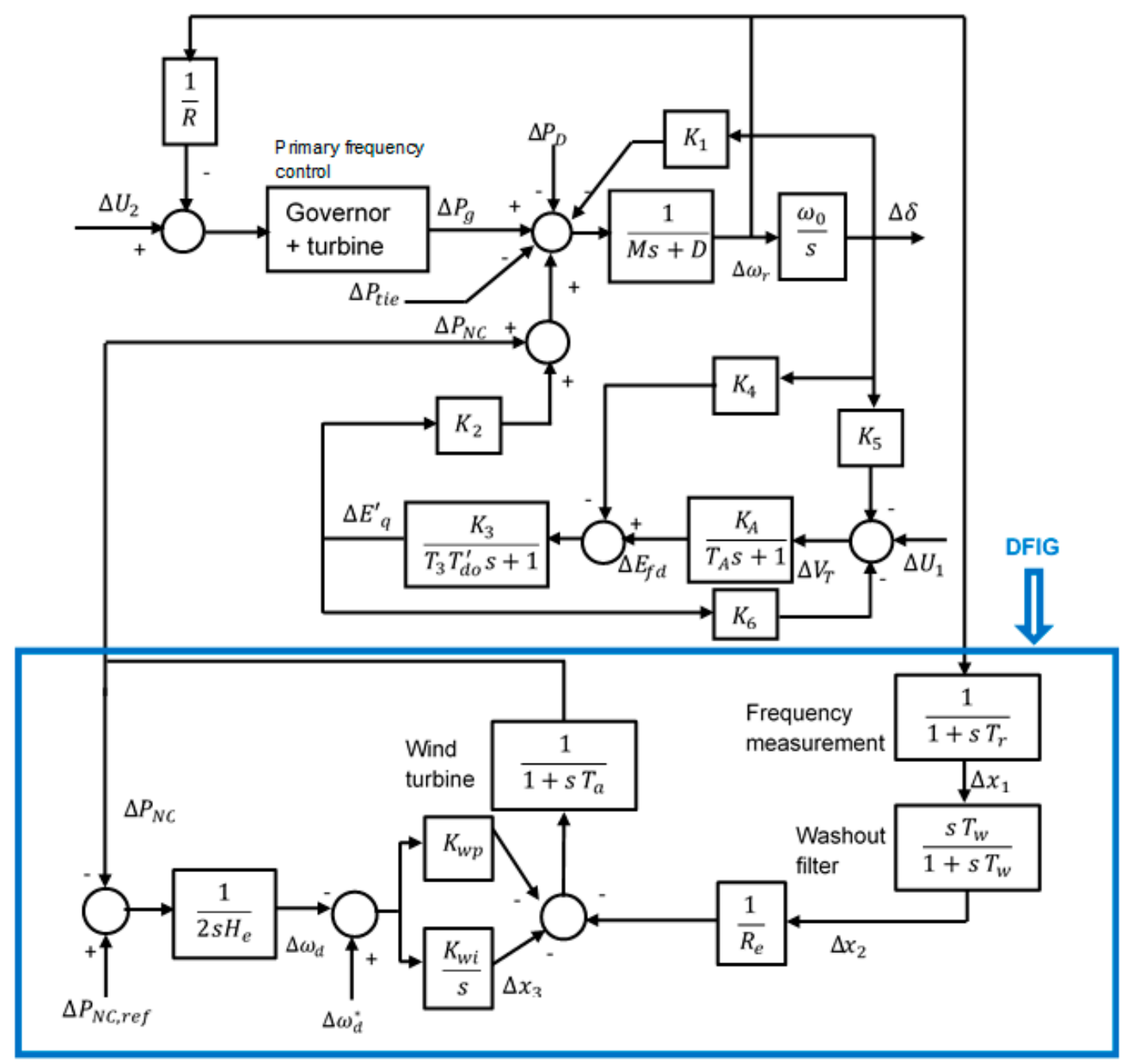

(c) Frequency control with DFIG mechanical model.

Figure 2. Linearized SG and DFIG combined machine model for power sharing.

Provided that the speed is given in a stationary reference frame, the developed linearized system is described in Equations (3)-(13), in which $\Delta \omega_{\mathrm{r}}$ and $\Delta \omega_{\mathrm{d}}$ are the speed deviations of the SG and the DFIG based machines, as follows:

$$
\begin{gathered}
\Delta \dot{\delta}=\omega_{o} \Delta \omega_{r} \\
\Delta \dot{\omega}_{r}=-\frac{K_{1}}{M} \Delta \delta-\frac{D}{M} \Delta \omega_{r}-\frac{K_{2}}{M} \Delta E_{q}^{\prime}+\frac{1}{M} \Delta T_{M}+\frac{1}{M} \Delta P_{N C}-\frac{1}{M} P_{d} \\
\Delta \dot{E}_{q}=-\frac{K_{4}}{T_{d o}} \Delta \delta-\frac{1}{K_{3} T_{d 0}} \Delta E_{q}+\frac{1}{T_{d 0}} \Delta E_{f d} \\
\Delta \dot{E}_{f d}=-\frac{K_{A} K_{5}}{T_{A}} \Delta \delta-\frac{K_{A} K_{6}}{T_{A}} \Delta E_{q}-\frac{1}{T_{A}} \Delta E_{f d}+\frac{K_{A}}{T_{A}} \Delta U_{1} \\
\Delta \dot{T}_{m}=-\frac{1}{T_{t}} \Delta T_{m}+\frac{1}{T_{t}} \Delta P_{g} \\
\Delta \dot{P}_{g}=-\frac{1}{R T_{g}} \Delta \omega_{r}-\frac{1}{T_{g}} \Delta P_{g}+\frac{1}{T_{g}} \Delta U_{2} \\
\Delta \dot{P}_{N C}=-\frac{1}{T_{a}} \Delta P_{N C}-\frac{1}{R_{e} T_{a}} \Delta x_{2}-\frac{1}{T_{a}} \Delta x_{3}+\frac{1}{K_{w p} T_{a}} \Delta \omega_{d}-\frac{1}{K_{w p} T_{a}} \Delta \omega_{d}^{*}
\end{gathered}
$$




$$
\begin{gathered}
\Delta \dot{x}_{1}=\frac{1}{T_{r}} \Delta \omega_{r}-\frac{1}{T_{r}} \Delta x_{1} \\
\Delta \dot{x}_{2}=\frac{1}{T_{r}} \Delta \omega_{r}-\frac{1}{T_{r}} \Delta x_{1}-\frac{1}{T_{w}} \Delta x_{2} \\
\Delta \dot{x}_{3}=-K_{w i}\left(\Delta \omega_{d}-\Delta \omega_{d}^{*}\right) \\
\Delta \dot{\omega}_{d}=-\frac{1}{2 H_{e}} \Delta P_{N C}+\frac{1}{2 H_{e}} \Delta P_{N C, r e f}
\end{gathered}
$$

where $\Delta \delta$ is the rotor angle deviation, $\Delta \dot{E}_{q}$ is the armature induced electromotive force, $\Delta E_{f d}$ is field winding or exciter electromotive force, $\Delta T_{m}$ is the developed mechanical torque, $\Delta P_{g}$ is the governor output power, $T_{t}$ and $T_{g}$ are turbine and the governor time constants, and $\Delta U_{1}$ and $\Delta U_{2}$ are control vectors. The state space variable form of the above system equations is given in the matrix form as in Equation (14), in which the superscript $T$ refers to matrix transposition and $\Delta P_{d}$ is the deviation of the load demands:

$$
\Delta \dot{X}=A \Delta X+B \Delta U+B_{d}\left[\Delta P_{d} \Delta P_{N C, r e f} \Delta \omega_{d}^{*}\right]^{T}
$$

\section{Problem Formulation}

The combination of the linear quadratic regulator (LQR) and Kalman filter culminates into the optimal LQG controller. First, an overview about the LQR and Kalman filter will be introduced. Finally, the LQG will be described.

\subsection{Linear Quadratic Regulator}

The controllable system is given in state space form as shown in Equation (14), where $X$ is the state vector of dimension $(11 \times 1), U$ is the control input of dimension $(2 \times 1)$, and $A, B$ are the system and input matrices, respectively, of appropriate dimensions. The state feedback controller is given as:

$$
U=-K X
$$

The LQR design procedures minimize a quadratic performance index as in Equation (16):

$$
\begin{gathered}
J=\int_{0}^{\infty}\left(X^{T} Q X+U^{T} R U\right) d t \\
\dot{X}=A_{c} X \\
A_{c}=A-B K
\end{gathered}
$$

If $S_{i}=s_{i R}+j s_{i i}$ is a closed loop pole of (18) and $\Lambda_{i}=\lambda_{i R}+j \lambda_{i i}$ is an open loop of (12), then a positive real parameter $\alpha_{i}$ exists to satisfy the optimality conditions as in Equation (19):

$$
\alpha_{i}=-\frac{s_{i R}+\lambda_{i R}}{2}
$$

Then, an algebraic equation can be formulated as in Equation (20):

$$
P(A+\propto I)+\left(A^{T}+\propto I\right) P-P B R^{-1} B^{T}+Q=0 .
$$

Under these conditions, the feedback gain vector is given as $K=R^{-1} B^{T}$ and $Q=2 \propto P$, where 


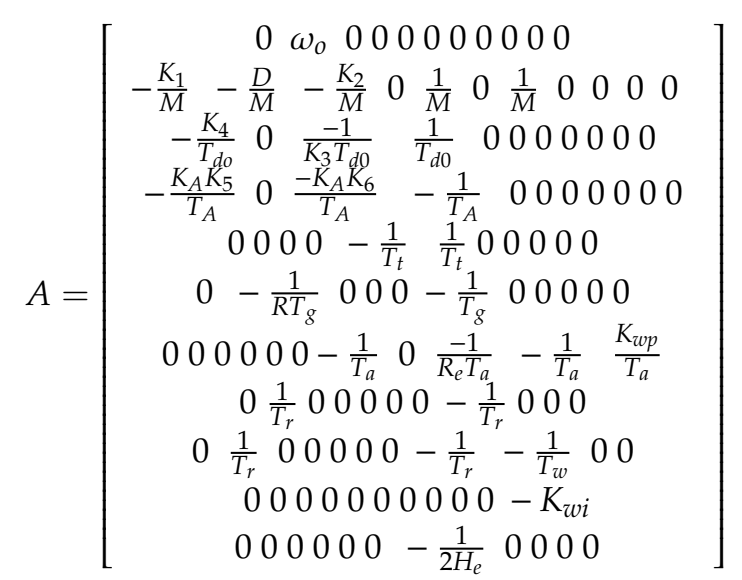

$$
\begin{aligned}
& \Delta X=\left[\Delta \delta \Delta \omega_{r} \Delta E^{\prime}{ }_{q} \Delta E_{f d} \Delta T_{M} \Delta P_{g} \Delta P_{N C} \Delta x_{1} \Delta x_{2} \Delta x_{3} \Delta \omega_{d}\right]^{T} \\
& \Delta U=\left[\begin{array}{ll}
\Delta U_{1} & \Delta U_{2}
\end{array}\right]^{T}
\end{aligned}
$$

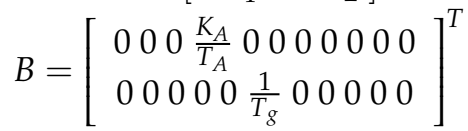

$$
\begin{aligned}
& B_{d}=\left[\begin{array}{c}
0 \frac{-1}{M} 00000000000 \\
000000000000 \frac{1}{2 H_{e}} \\
000000 \frac{-1}{K_{w p} T_{a}} 00-K_{w i} 0
\end{array}\right]^{T}
\end{aligned}
$$

\subsection{Kalman Filter}

The LQR implementation requires all the system states to be measurable for proper feedback. However, internal states are not available in most cases. Designing an appropriate controller requires an observer for the inaccessible states. This depends on measuring the output states. Such state observer is interpreted as Kalman filter when noise is considered. The onward observer optimality is guaranteed using noise signals as given in Equations (21) and (22), respectively:

$$
\begin{aligned}
& \dot{X}=A X+B U+\omega \\
& Y=C X+D U+v
\end{aligned}
$$

where $A, B, C, D$ are the plant state space variable matrices, $\omega$ : the input process noise vector, and $v$ is the output measurement noise vector. The optimal observer is given by:

$$
\hat{\dot{X}}=A \hat{X}+B U+L(Y-C \hat{X}),
$$

where $\hat{X}$ is the observer estimation for the variable states $X$, and $L$ is the Kalman filter gain matrix and calculated as:

$$
L=P C^{T} v
$$

The Kalman filter gains can be computed by into solving the algebraic Riccati equation as in Equation (23):

$$
A P+P A^{T}-P C^{T} V^{-1} C P+B \omega B^{T}=0
$$

\subsection{Linear Quadratic Gaussian}

LQG has significant impact to damp out the synchronous generator rotor speed deviations, particularly if the wind uncertainties or measurement noises are considered. Due to the separation principle, the LQR and the Kalman filter are designed separately. Combining the LQR and the Kalman filter together leads to the so-called LQG controller demonstrated in Figure 3, in which $\hat{X}$ and $\hat{Y}$ are the 
observer estimation for the variable input and output states. The plant shown in Figure 3a corresponds to the Equations (3)-(13), which are embedded in Equation (14). As shown in Figure 3b, the operation based on the LQG controller starts by reading the parameters of each machine, the DFIG rotor speed, the output power deviations, and the loading conditions. Then, the LQR is constructed with the help of designing the matrices $Q$ and $R$ as in Equation (14). It is worth mentioning that the process noise in this hybrid machine system appears in the measurements of the frequency, the wind speed, and power. In turn, a noise filter design is considered according to Equation (26):

$$
J^{\prime}=\int_{0}^{\infty}\left(X^{T} Q_{0} X+U^{T} R_{0} U\right) d t
$$

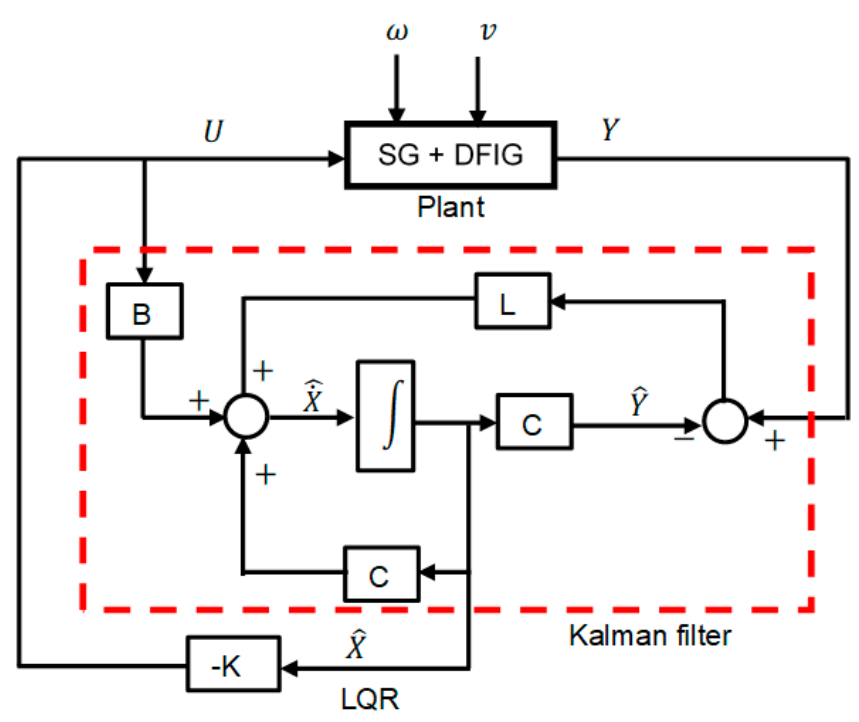

(a) Linear quadratic Gaussian controller.

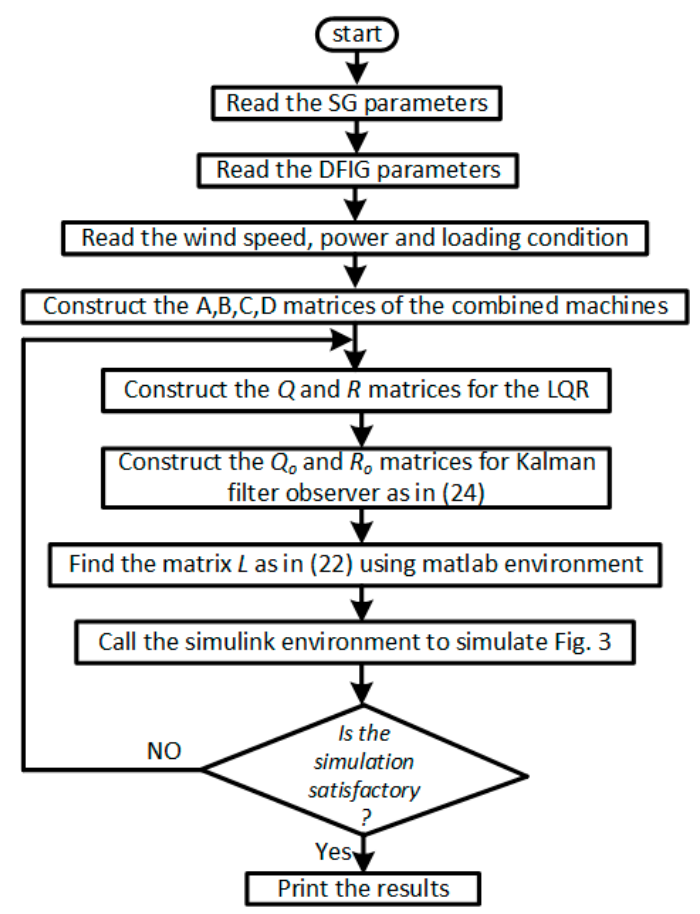

(b) A flow chart to show the operation of the system based on the LQG approach.

Figure 3. Numerical solution flow chart of the combined machines association via LQG approach. 
Thus, the proper design of the Kalman filter matrices $Q_{o}$ and $R_{o}$ is related to the power of the process and measurements noises. Finally, the simulation is performed as shown in Figure 3a. The output signal $Y$ depends on the assigned $C$ array. In particular, the rotor speed and rotor angle deviations were utilized to estimate the other states using the Kalman filter, which can reduce the required sensors and transducers in real applications. In addition, the developed approach is straightforward with low computational complexity.

\subsection{Pole Placement Control}

The study of the characteristic polynomial of the DFIG association with the conventional synchronous generator is given as (sI-(A-BK)), in which $I$ is the identity matrix, $A$ and $B K$ are the 11 by 11 matrix. The study of this matrix demonstrates that this characteristic polynomial has two complex poles. The feedback design procedures are thus to shift the real part of the complex poles ten times on the left-hand side of the s-plane, thereby moving the poles to the desired location at the expense of the control vector $K$.

\section{Simulated Results}

The work in this study is considered a power system stabilizer (PSS) since the control signal $\Delta U_{1}$ modifies the exciter voltage. To cover the uncertainties embedded in the wind speed, power, and the synchronous machine parameters, which is highly affected by the loading conditions, several operating and load conditions are investigated. In addition, the robustness of the designed controller at the SG association with the DFIG-based wind turbine is investigated with several test cases. With the formulation of the combined machines described above, a linearized system in a stationery reference frame of the SG association with DFIG and the developed controller are implemented via Matlab/Simulink 2015a with a target to prove the efficacy of the developed controller against such inherent uncertainties. The parametric values of DFIG based system is given in Appendix A.

Provided that the system parameters of the SG given in the appendices are being changed with loading conditions and power factor, the matrices $Q$ and $R$ in Equation (14) are chosen as:

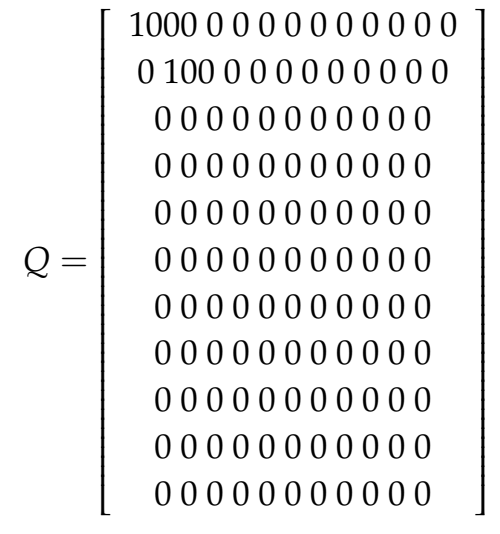

$$
\begin{aligned}
& R=\left[\begin{array}{cc}
20 & 0 \\
0 & 20
\end{array}\right]
\end{aligned}
$$

The observer filter matrices $Q_{o}$ and Ro are designed as:

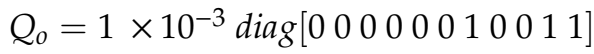

$$
\begin{aligned}
& R_{0}=1 \times 10^{-8} \times\left[\begin{array}{ll}
1 & 0 \\
0 & 1
\end{array}\right]
\end{aligned}
$$

The observer gain matrices are given by: 


$$
\begin{aligned}
K & =\left[\begin{array}{c}
-0.35-333.895 .050 .03-3.55-0.62-3.24-0.190 .551 .32-2.09 \\
0.19189 .31-2.85-0.022 .00 .341 .840 .09-0.29-0.691 .10
\end{array}\right] \\
L & =\left[\begin{array}{c}
47.543 .01-0.2326 .05-0.060-0.65408 .391 .011 .003-96.94308 .47 \\
3.010 .29-0.010 .743-0.002-0.0549 .570 .070 .075-12.2439 .39
\end{array}\right]
\end{aligned}
$$

For the pole placement technique, the desired poles vector is decided as

$$
\begin{gathered}
P=[-0.363-7.0288 \mathrm{i},-0.363+7.0288 \mathrm{i}-14.2948,-12.5179,-10.0274,-4.6976, \\
-3.6871,-2.7609,-0.1745,-0.1652,-0.1020]
\end{gathered}
$$

Additionally, the control gain matrix is given as:

$$
K_{\text {pole placement }}=\left[\begin{array}{c}
0.057-1.698-0.024-0.0037-0.04-0.011-0.039-0.0150 .0220 .0910 .18 \\
-0.254 .90-2.48-0.0870 .2660 .17570 .24330 .262-0.3060 .103-0.393
\end{array}\right]
$$

\subsection{Scenario 1: Step Change in the Power Demand}

A 0.05 pu step load demand disturbance is applied at normal load (i.e., $P=1 \mathrm{pu}, Q=0.25 \mathrm{pu}$ [2]). Figure $4 \mathrm{a}, \mathrm{b}$ shows the rotor speed and rotor angle transient digressions responses. For the LQG controller, the control signal vector is shown in Figure 4c. The open loop system is still stable with the DFIG-based wind turbine. The insertion of DFIG-based wind turbine makes the system without controllers suffer from damped oscillations, which is an undesirable response compared with the designed LQG controller. The pole placement technique demonstrates longer settling time to dampen out the rotor speed oscillations. The designed LQG with the DFIG-based wind turbine controller gives satisfactory results. The control vector inputs are stable and bounded. In addition, it can suppress all oscillations efficiently.

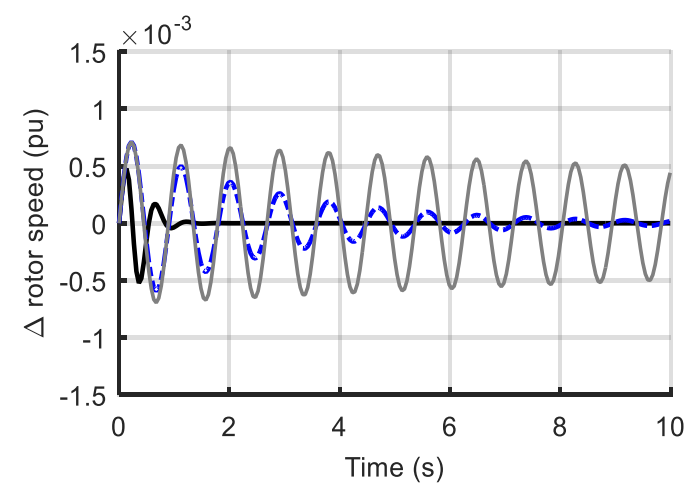

(a)

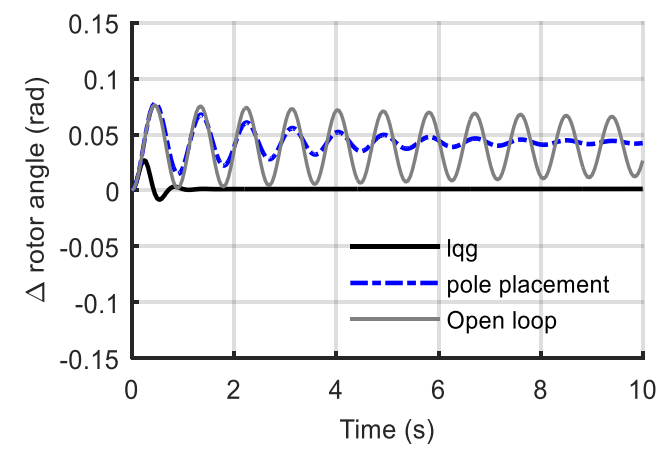

(b)

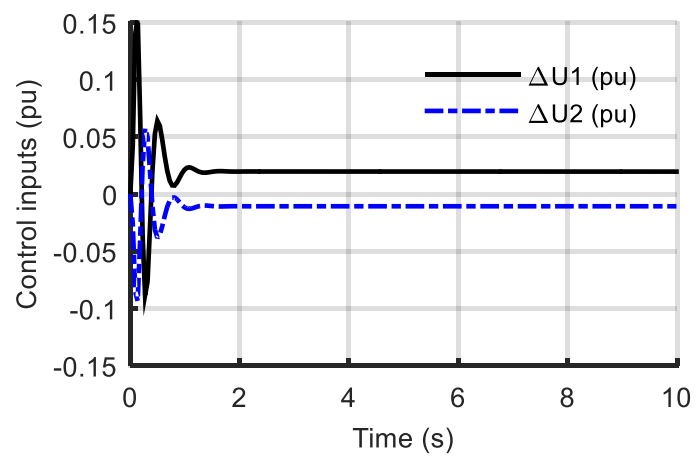

(c)

Figure 4. SG performance due to $0.05 \mathrm{pu}$ step load demand at $\mathrm{P}=1 \mathrm{pu}, \mathrm{Q}=0.25 \mathrm{pu}$. (a) rotor speed deviation; (b) rotor angle deviation; (c) LQG control vector inputs. 


\subsection{Scenario 2: Impact of Light Loads}

In this scenario, a $0.05 \mathrm{pu}$ step load demand was applied at a light load of $\mathrm{P}=1.1, \mathrm{Q}=0.1 \mathrm{pu}$. Figure 5 demonstrates the rotor speed and rotor angle transient digressions' responses. The applied load of the DFIG based wind turbine association with synchronous generator makes the system without a controller suffer from undamped oscillations regarding the rotor speed deviations, which thus results in instability in the long term. Without control, the original system conducted in [2] was investigated to be stable with suppressed oscillation at light loads. The insertion of the DFIG generator thereby undermines the system stability. The whole system inertia might decrease slightly, which results in the undamped oscillations response. It is clear that the developed LQG controller is still powerful in damping out all oscillations and the robustness of the developed controller is confirmed.

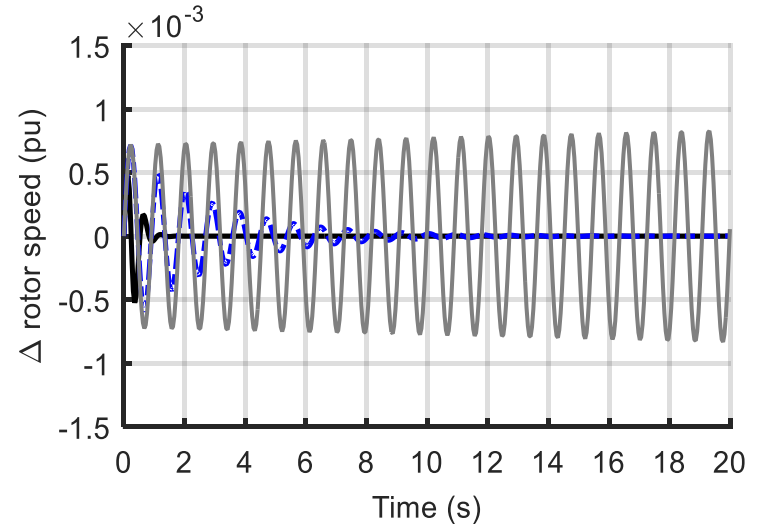

(a)

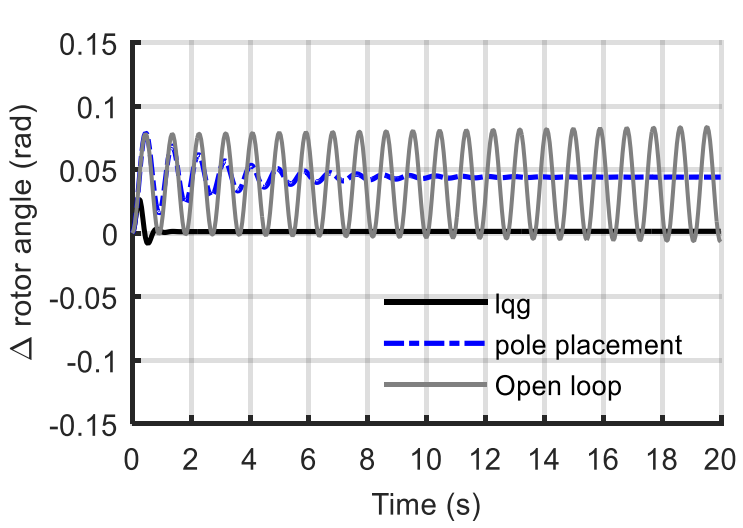

(b)

Figure 5. SG performance due to $0.05 \mathrm{pu}$ step load demand at $\mathrm{P}=1.1 \mathrm{pu}, \mathrm{Q}=0.1 \mathrm{pu}$. (a) Rotor speed deviation; (b) Rotor angle deviation.

\subsection{Scenario 3: Impact of Heavy and Lead Power Factor Loads}

In this scenario, a $0.05 \mathrm{pu}$ step load demand was applied at $(\mathrm{P}=1 \mathrm{pu}, \mathrm{Q}=-0.25 \mathrm{pu})$ and $(\mathrm{P}=1 \mathrm{pu}, \mathrm{Q}=-0.8 \mathrm{pu})$. Figure 6 shows the rotor speeds transient digressions responses for both cases, respectively. As expected, the open loop system is unstable at heavy and lead power factor loads. The developed LQG controller demonstrates satisfactory behavior. It is more efficient in enhancing the damping characteristics of the DFIG-based wind turbine association with a leader synchronous thermal power system.

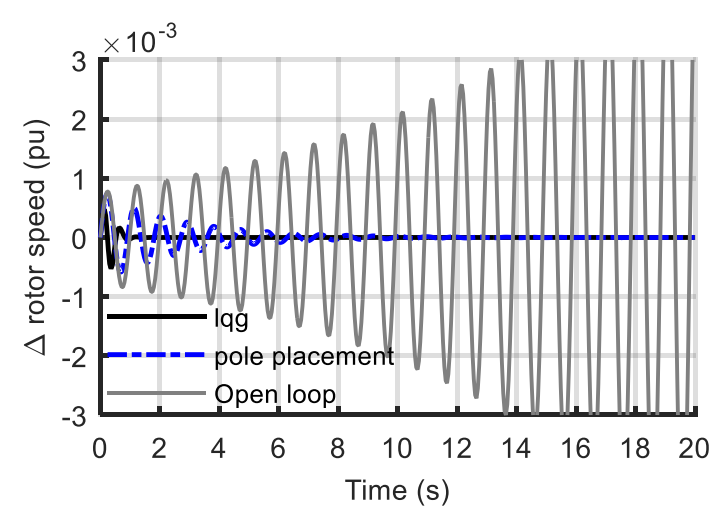

(a)

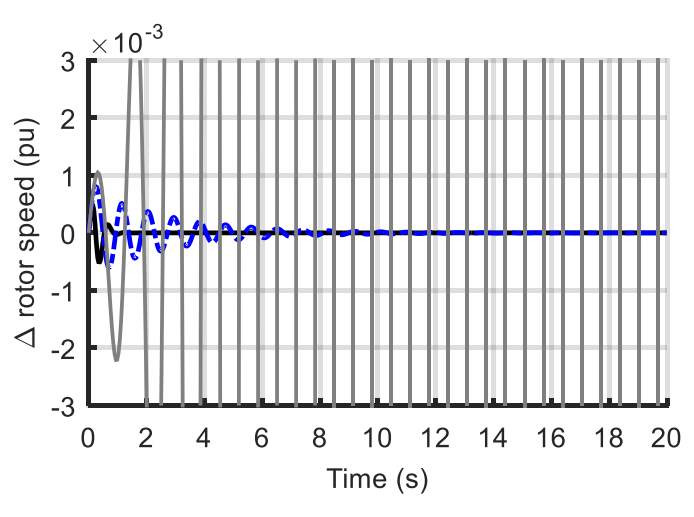

(b)

Figure 6. SG rotor speed deviations due to $0.05 \mathrm{pu}$ step load demand at lead power factor. (a) At $\mathrm{P}=1$ pu, $Q=-0.25 \mathrm{pu}$; (b) At $\mathrm{P}=1 \mathrm{pu}, \mathrm{Q}=-0.8 \mathrm{pu}$. 


\subsection{Scenario 4: Impact of DFIG Nonconventional Wind Power Contribution}

The power produced by the DFIG based machine is called in this context nonconventional power to treat it as different from the conventional synchronous generator power. With the conditions of scenario 1, the deviation in the nonconventional power is given in Equation (27), in which $\alpha$ is the wind energy participation index:

$$
\alpha=\frac{P_{N C}}{P_{g}}
$$

where

$P_{N C}:$ is the total wind generation,

$P_{g}:$ is the total generated conventional power.

To investigate the capability of the developed LQG controller due to the contribution of wind energy penetration growth in the total power system, several values of $\alpha$ will be considered in this scenario. Some of the system performances are given from Figure 7. More wind power penetration into the power system increases the steady state rotor angle. In addition, it results in transient overshoot in the speed deviations. Thus, the capability of the developed LQG controller is proved satisfactorily in solving such load frequency problem.

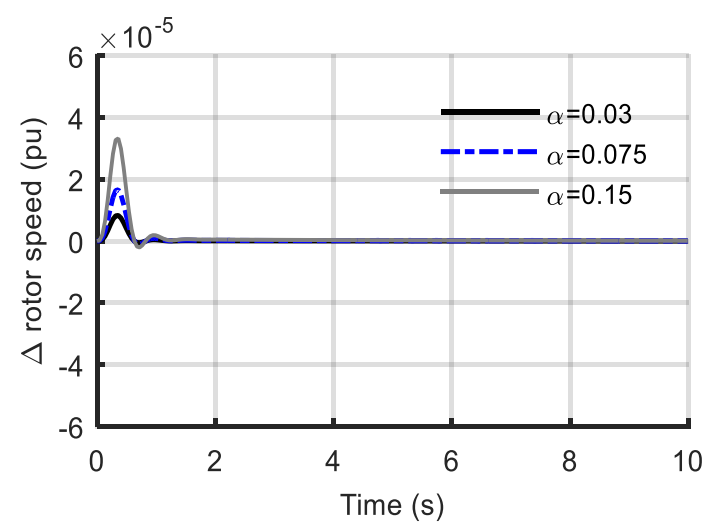

(a)

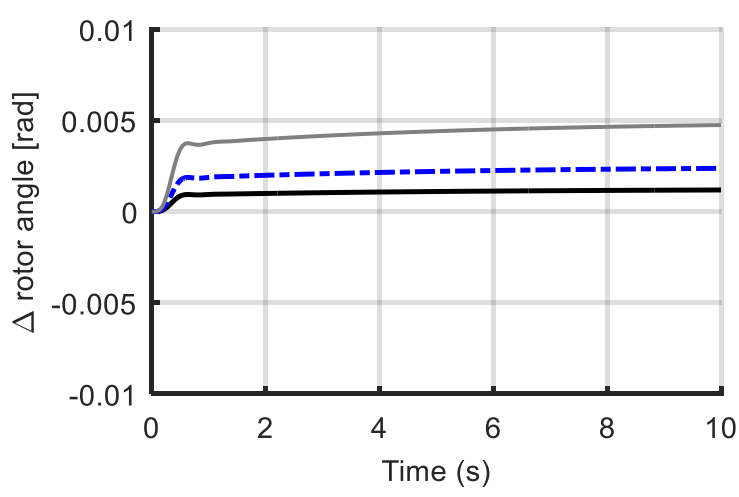

(b)

Figure 7. SG performance with considering wind power impact at $\mathrm{P}=1 \mathrm{pu}, \mathrm{Q}=0.25 \mathrm{pu}$. (a) Rotor speed deviation; (b) rotor angle deviation.

\subsection{Scenario 5: Impact of DFIG Wind Speed Deviations}

The impact of the wind speed is investigated at the normal load. The system performances are shown in Figure 8. The increase in wind speeds results in increasing the transient over/under shoots of the conventional synchronous machine rotor speeds and angle deviations. Due to the wind speed intermittent nature, the DFIG-based wind turbine output power is vulnerable for speed variations, which yields a noise signal from the instruments used to sense wind speed signal [31]. Such speed variation can be represented in process noise. The significant appeal for the LQG control is its ability to maintain the stability against the process noise. To demonstrate the robustness of the developed controller, a noise signal with signal to noise ratio (SNR) of 0.005 (i.e., $46 \mathrm{~dB}$ ) is superimposed to the wind speed signal. The impact of the wind speed noise upon the conventional machine rotor speed is shown in Figure 9. It is clear that the rotor speed deviations of the synchronous machine are bounded. Thus, the robustness of the developed controller in solving the load frequency problem against wind speed process noise was affirmed. 


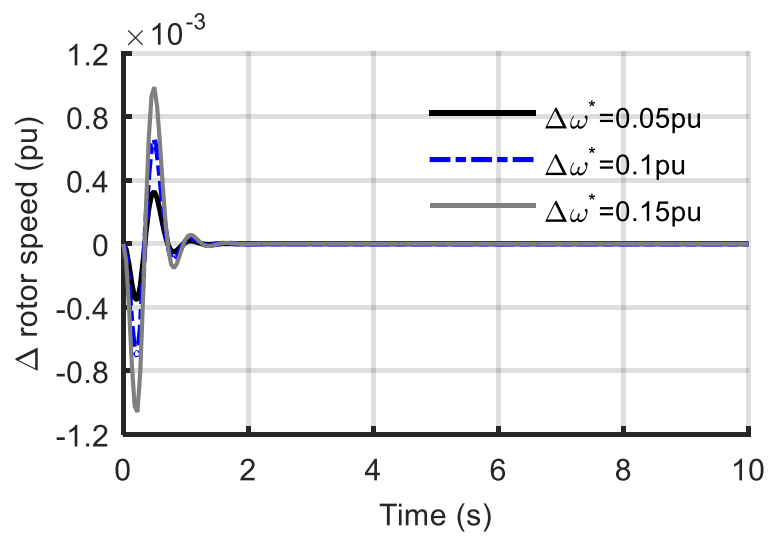

(a)

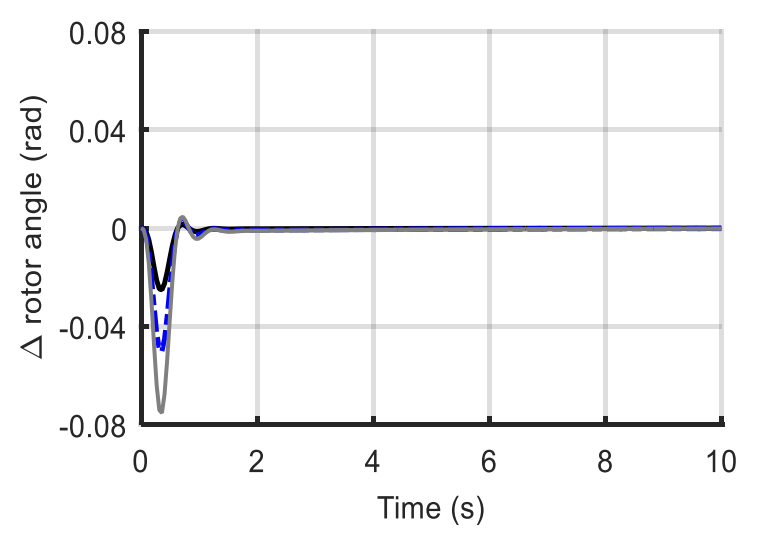

(b)

Figure 8. SG performance with considering wind speed impact at $\mathrm{P}=1 \mathrm{pu}, \mathrm{Q}=0.25 \mathrm{pu}$. (a) Rotor speed deviation; $(\mathbf{b})$ rotor angle deviation.

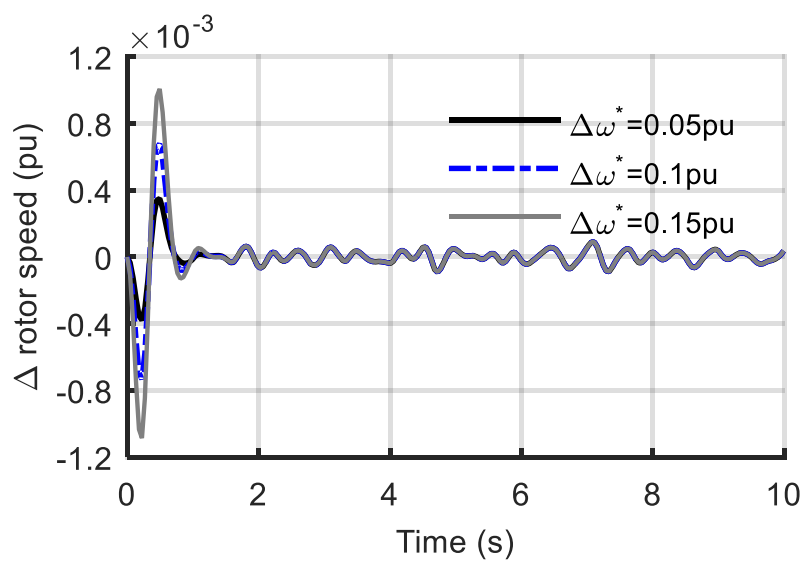

Figure 9. Rotor speed deviations with considering wind speed intermittent nature impact.

\subsection{Impact of the SG Speed Deviation on the Stability of the WEC System}

One of the objectives of this study is to ensure stability of the WEC system based on the DFIG. Unlike SGs, DFIG based machines can operate above or below the synchronous speed to harvest the maximum wind energy. However, the changes of the SG rotor speed vary the delivered output power and the frequency of the transmission line, which affects the power sharing transient operation. Under the same operating conditions of scenario 1, Figure 10 demonstrates the response of the DFIG at the normal load where the SG rotor speed deviations demonstrated in scenario 1 affect the behavior of the DFIG machine. It is obvious that the developed LQG controller can dampen the DFIG rotor speed and the output power deviations.

\subsection{Settling Time}

The settling time is the time taken for a state to reach within $2 \%$ of its steady state. Table 1 gives several settling times values of previously reported results from the literature. Generally, the studied done before under load frequency control area are divided into interconnected area with and without renewables. The developed LQG here outperforms the other approaches, as given in Table 1, which shows a settling time of $1.28 \mathrm{~s}$. It should be noted that meta-heuristic algorithms, which involve heavy computations, give relatively larger values for the settling time. 


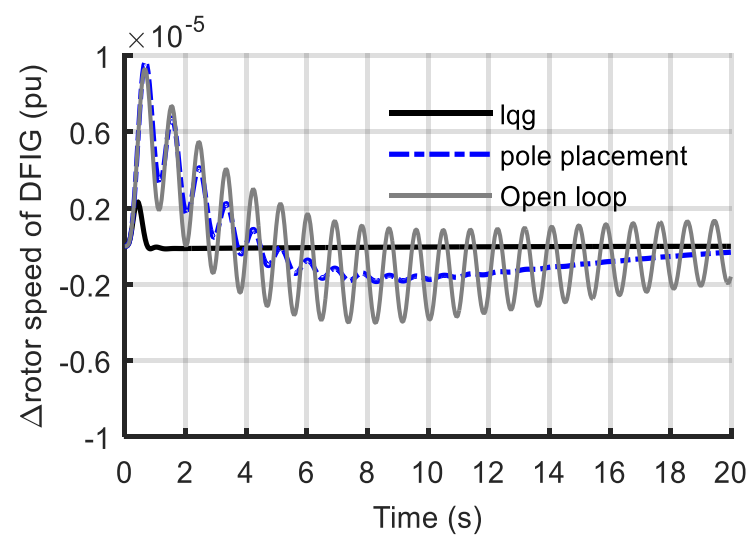

(a)

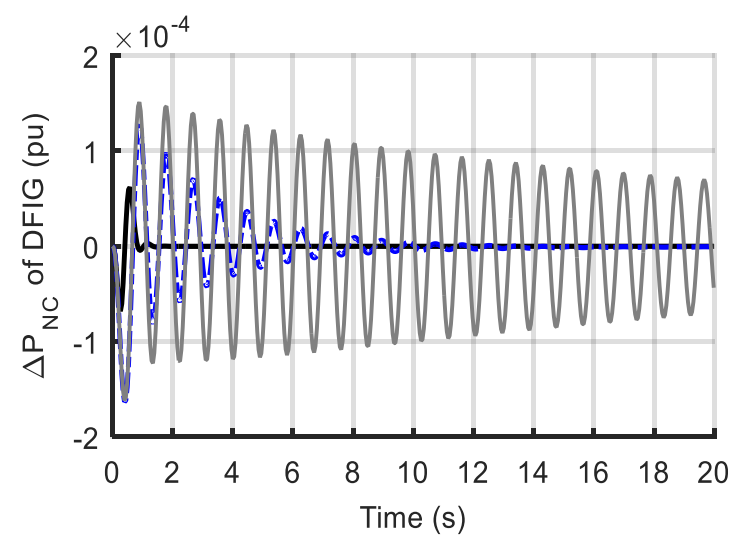

(b)

Figure 10. DFIG performance due to 0.05 pu step load demand at $P=1.0 \mathrm{pu}, \mathrm{Q}=0.25 \mathrm{pu}$. (a) DFIG rotor speed deviation; (b) DFIG power output deviation.

Table 1. Settling time of interconnected power systems at normal load (s).

\begin{tabular}{cccccccccc}
\hline \multicolumn{4}{c}{ With DFIG } & \multicolumn{4}{c}{ Without DFIG } \\
\hline Without & Pole & LQG & IHS & MILP & AC & ANFIS & Pole-shifting & Pole & CS \\
control & placement & [14] & {$[24]$} & {$[20]$} & {$[33]$} & control [2] & placement [2] & {$[34]$} \\
19.9 & 10.6 & 1.28 & 22.5 & $\sim 150$ & 19.5 & 31.6 & 1.3 & 15 & 25.9 \\
\hline
\end{tabular}

\section{Discussion}

From the above case studies and load conditions, the following remarks can be drawn:

- Since SGs with damping torques are stable systems, it is common to include open loop simulations $[10,11]$ together with closed-loop results in order to assess the quality of the response and to show the consequences of control failure, which can be very useful information for safety considerations. Since the damping coefficient $D$ is set to zero in the studied cases, the open loop machines combination is being vulnerable for load changes and operating conditions. The results here demonstrate that the synchronous generator response changes from sustained oscillations in open loop to completely damped response in closed loop under heavy loading conditions.

- At normal load, the system maintains its stability with and without the developed controllers as in Figure 4.

- At light, heavy, and leading power factors, the system is unstable without control. However, the developed controller has a high capability to stabilize the hybrid distributed interconnected DER system with the DFIG-based wind turbine.

- The developed controller is able to keep the system stability due to the changes on the nonconventional wind power production.

- $\quad$ The speed deviations response is bounded due to the wind speed noise as in Figure 9.

- The impact of wind speed upon the synchronous generator speed and angle deviations is stronger compared to the impact of DFIG nonconventional power.

- The designed DFIG shows satisfactory performance compared to previously reported results in terms of the settling time as shown in Table 1.

- The impacts of the SG rotor speed and angle deviations on the performance of the DFIG output power as shown in Figure 10 can lead to changes of the operation of the WEC system from the maximum power point tracking curves.

- In this work, only the results are limited to the synchronous generator rotor speed and angle deviation. The reason is related to the nature of synchronous machines, whereby the rotor is 
twisted due to such deviations unlike DFIG rotor, which could operate satisfactorily at sub or super the synchronous speed.

- Another limitation is related to nature of this work, which can only be applied for WEC systems. It should be modified to adapt other renewables such as PVs, which have no rotating mass and different techniques to collect the maximum energy [35]. However, this work is more generic than the straightforward approach in $[36,37]$ whereby only automatic voltage regulators were considered.

\section{Conclusions}

The paper has tackled the power sharing problem among hybrid DERs impact upon the rotor speed of the leader synchronous generator. The problem of load frequency with DFIG-based wind turbine association with a leader synchronous generator was thus considered via linear quadratic Gaussian controller. The developed controller has a high capability to keep the system stability under various loading conditions. The nobility of the developed LQG controller was elucidated by using various DFIG-based wind turbine participation and wind speed ratios. From the simulation results and discussions, the following conclusions can be drawn, and (1) the developed controller is simple and has a high capability to damp oscillations fast with small settling times. In addition, the developed controller avoids complicated signal measurements as it relies on a Kalman filter observer design and receives only the rotor speed and rotor angle information from the leader synchronous generator, (2) the impact of wind speed deviations on the synchronous generator rotor speed is stronger when compared to wind power penetrations. The wind power deviations seem to modify the rotor angle at the long term operating conditions, (3) At light and lead power factor loads, the modified Concordia model is unstable; thus, the proposed LQG controller shows satisfactory behavior, (4) despite the wind speed uncertainties, the proposed LQG helps make the rotor speed deviations of the leader synchronous generator bounded.

For the purpose of future work, the developed hybrid state space is to be applied for a decentralized multi-area interconnected power system with various thermal and hydro units. In addition, modern renewable energy resources such as photovoltaics or hydrogen energy storage systems impact upon the leader synchronous machine are to be considered.

Author Contributions: F.K.A.-E. has performed conceptualization, visualization, and manuscript writing. A.M.Y. has contributed to the conceptualization. The software, methodology, and validation were achieved by F.K.A.-E., and H.S.A., Z.M.A. has carried out the visualization and manuscript editing. M.S.N. and Z.M.A. have contributed to writing and editing. The visualization, writing, and manuscript editing were carried out by N.V.Q. All authors have read and agreed to the published version of the manuscript.

Funding: This research receives no external funding.

Acknowledgments: The authors acknowledge Lac Hong University, Vietnam for the exceptional support of this work.

Conflicts of Interest: The authors declare no conflict of interest.

\section{Acronyms}

DFIG doubly fed induction generator

DER distributed energy resource

WEC wind energy conversion

LFC load frequency control

LQG linear quadratic Gaussian

LQR linear quadratic regulator

PSS power system stabilizer

SG synchronous generator 


\section{Appendix A}

The constants of the DFIG based wind turbine are [38]: $\mathrm{Tr}=0.1, \mathrm{Tw}=6, \mathrm{Ta}=0.2, \mathrm{He}=3, \mathrm{Re}=2.4$.

\section{References}

1. Toulabi, M.; Bahrami, S.; Ranjbar, A.M. An input-to-state stability approach analysis of doubly-fed induction generator-based wind turbines. IEEE Trans. Energy Conv. 2017, 32, 1418-1431. [CrossRef]

2. Yousef, A.M.; Kassem, A.M. Optimal pole shifting controller for interconnected power system. Energy Convers. Manag. 2011, 52, 2227-2234. [CrossRef]

3. Shintai, T.; Miura, Y.; Ise, T. Oscillation damping of a distributed generator using a virtual synchronous generator. IEEE Trans. Power Deliv. 2014, 29, 668-676. [CrossRef]

4. Aboelyousr, F.K.; Elnozahy, A.; Nozhy, A.N. Bi-objective economic feasibility of hybrid micro-grid systems with multiple fuel options for islanded areas in Egypt. Renew. Energy 2018, 128, 37-56. [CrossRef]

5. Nand, K.; Saini, R.P.; Singh, S.P. Optimal pole shift control in application to a hydro power plant. J. Electr. Eng. 2005, 56, 290-297.

6. Abo-Elyousr, F.K.; Sharaf, A.M. A novel modified robust load frequency controller scheme. Energy Syst. 2019, 11, 1175-1198. [CrossRef]

7. Aboelyousr, F.K.; Abdelaziz, A.Y. A Novel modified robust load frequency control for mass-less inertia photovoltaics penetrations via hybrid PSO-WOA approach. Electr. Power Compon. Syst. 2019, 47, 1744-1758. [CrossRef]

8. Attya, A.; Anaya-Lara, O.; Leithead, W. Novel concept of renewables association with synchronous generation for enhancing the provision of ancillary services. Appl. Energy 2018, 229, 1035-1047. [CrossRef]

9. Fargani, M.F.; Saeid, K.; Saeid, H.; Hossein, N.P. Coordinated control of low-frequency oscillation using real immune algorithm with population management. Energy Convers Manag. 2010, 51, 271-276.

10. El-Sherbiny, M.; El-Saady, G.; Yousef, A.M. Efficient fuzzy logic load-frequency controller. Energy Convers. Manag. 2002, 43, 1853-1863. [CrossRef]

11. El-Sherbiny, M.; Hasan, M.; El-Saady, G.; Yousef, A.M. Optimal pole shifting for power system stabilization. Electr. Power Syst. Res. 2003, 66, 253-258. [CrossRef]

12. Brogliato, B.; Lozano, R.; Maschke, B.; Egeland, O. Positive real systems. In Dissipative Systems Analysis and Control; Springer: Cham, Switzerland, 2020; pp. 9-79. [CrossRef]

13. Abo-Elyousr, F.K. Load frequency controller with virtual inertia generator for interconnected power systems via artificial bee colony. In Proceedings of the Middle East Power System Conference (MEPCON), Cairo University, Cairo, Egypt, 18-20 December 2018; Volume 1, pp. 367-372.

14. Aboelyousr, F.K.; Youssef, A.M.; Abdelaziz, A.Y. Multi-area hydrothermal interconnected load frequency control with double-fed induction-generator-based wind turbine via improved harmony algorithm. Electr. Power Compon. Syst. 2018, 46, 615-628. [CrossRef]

15. Ahmadi, R.; Sheikholeslami, A.; Niaki, A.N.; Ranjbar, A. Dynamic participation of doubly fed induction generators in multi-control area load frequency control. Int. Trans. Electr. Energy Syst. 2014, 25, 1130-1147. [CrossRef]

16. Lara, O.L.; Hughes, F.M.; Jenkins, N. Contribution of DFIG-based wind farms to power system short-term frequency regulation. Wind Energy 2006, 15, 164-170.

17. Mullane, A.; O'Malley, M. The inertial response of induction-machine-based wind turbines. IEEE Trans. Power Syst. 2005, 20, 1496-1503. [CrossRef]

18. Pandey, S.K.; Mohanty, S.R.; Kishor, N. A literature survey on load-frequency control for conventional and distribution generation power systems. Renew. Sustain. Energy Rev. 2013, 25, 318-334. [CrossRef]

19. Sun, Y.-Z.; Zhang, Z.-S.; Li, G.-J.; Lin, J. Review on frequency control of power systems with wind power penetration. In Proceedings of the 2010 International Conference on Power System Technology; Institute of Electrical and Electronics Engineers (IEEE), Hangzhou, China, 24-28 October 2010; Volume 1, pp. 1-8.

20. Abo-Elyousr, F.K. Load frequency controller design for two area interconnected power system with DFIG based wind turbine via ant colony algorithm. In Proceedings of the Middle East Power System Conference (MEPCON), Cairo, Egypt, 27-29 December 2016; Volume 1, pp. 253-260.

21. Bhatt, P.; Roy, R.; Ghoshal, S. Dynamic participation of doubly fed induction generator in automatic generation control. Renew. Energy 2011, 36, 1203-1213. [CrossRef] 
22. De Almeida, R.G.; Lopes, J.P. Participation of Doubly fed induction wind generators in system frequency regulation. IEEE Trans. Power Syst. 2007, 22, 944-950. [CrossRef]

23. Gomez, L.A.; Bueno, B.G.; Grilo, A.P.; Filho, A.J.; Salles, M. Analysis of the doubly fed induction generator performance of frequency support microgrids. In Proceedings of the Power Symposium (NAPS), Morgantown, WV, USA, 17-19 September 2017; Volume 1, pp. 17-19.

24. Fernández-Guillamón, A.; Sarasúa, J.I.; Chazarra, M.; Vigueras-Rodríguez, A.; Fernández-Muñoz, D.; Molina-García, Á. Frequency control analysis based on unit commitment schemes with high wind power integration: A Spanish isolated power system case study. Int. J. Electr. Power Energy Syst. 2020, 121, 106044. [CrossRef]

25. Duong, M.Q.; Nguyen, H.H.; Le, K.H.; Phan, T.V.; Mussetta, M. Simulation and performance analysis of a new LVRT and damping control scheme for DFIG wind turbines. In Proceedings of the International Conference on Sustainable Energy Technologies, Hanoi, Vietnam, 14-16 November 2016; Volume 1, pp. 288-294.

26. Kassem, A.M.; Yousef, A.M. Robust control of an isolated hybrid wind-diesel power system using linear quadratic Gaussian approach. Int. J. Electr. Power Energy Syst. 2011, 33, 1092-1100. [CrossRef]

27. Mohamed, T.H.; Diab, A.A.Z.; Hussein, M.M. Application of linear quadratic Gaussian and coefficient diagram techniques to distributed load frequency control of power systems. Appl. Sci. 2015, 5, 1603-1615. [CrossRef]

28. Al-Digs, A.; Chen, Y.C. Generation and load balance using linear quadratic Gaussian control; North American Power Symposium (NAPS): Denver, CO, USA, 2016; Volume 1, pp. 18-20.

29. Ali, M.; Zahra, S.T.; Jalal, K.; Saddiqa, A.; Hayat, M.F. Design of optimal linear quadratic gaussian (LQG) controller for load frequency controller (LFC) using genetic algorithm (GA) in power systems. Int. J. Eng. Work. 2018, 5, 40-49.

30. Ali, M.; Hassan, M.E. Multi-area load frequency control (LFC) for power system using linear quadratic gaussian (LQG). Aust. J. Eng. Technol. Res. 2017, 2, 120-132.

31. Hu, Y.; Wei, W. Improved droop control with washout filter. Energies 2018, 11, 2415. [CrossRef]

32. Shan, Y.; Hu, J.; Liu, M.; Zhu, J.; Guerrero, J.M. Model predictive voltage and power control of islanded PV-battery microgrids with washout-filter-based power sharing strategy. IEEE Trans. Power Electron. 2020, 35, 1227-1238. [CrossRef]

33. Khuntia, S.R.; Panda, S. Simulation study for automatic generation control of a multi-area power system by ANFIS approach. Appl. Soft Comput. 2012, 12, 333-341. [CrossRef]

34. Abdelaziz, A.Y.; Ali, E. Load frequency controller design via artificial cuckoo search algorithm. Electr. Power Compon. Syst. 2015, 44, 90-98. [CrossRef]

35. Abo-Elyousr, F.K.; Abdelshafy, A.M.; Abdelaziz, A.Y. MPPT-Based particle swarm and cuckoo search algorithms for PV systems. In Modern Maximum Power Point Tracking Techniques for Photovoltaic Energy Systems; Springer: Cham, Switzerland, 2020; pp. 379-400.

36. Micev, M.; Ćalasan, M.; Ali, Z.M.; Hasanien, H.M.; Aleem, S.H.A. Optimal design of automatic voltage regulation controller using hybrid simulated annealing-Manta ray foraging optimization algorithm. Ain Shams Eng. J. 2020, in press. [CrossRef]

37. Ali, Z.M. Power system conventional stabilizers \& automatic voltage regulator gain effects on torque coefficients. Int. J. Emerg. Technol. Adv. Eng. IJETAE 2012, 2, 365-368.

38. Jalali, M. DFIG Based Wind Turbine Contribution to System Frequency Control. Master's Thesis, University of Waterloo, Waterloo, ON, Canada, 2001.

(C) 2020 by the authors. Licensee MDPI, Basel, Switzerland. This article is an open access article distributed under the terms and conditions of the Creative Commons Attribution (CC BY) license (http://creativecommons.org/licenses/by/4.0/). 